\title{
Mechanisms of Epigenetic Toxicity in the Pathogenesis of Cancer for "Precision Medicine"
}

James E. Trosko

Department of Pediatrics/Human Development, College of Human Medicine, Michigan State University, East Lansing, Michigan, USA

\section{Article Info}

\section{Article Notes}

Received: September 4, 2018

Accepted: November 30, 2018

\section{*Correspondence:}

Dr. James E. Trosko, Professor Emeritus, Department of Pediatrics and Human Development, College of Human Medicine, Michigan State University, 1355 Bogue St. B240, East Lansing, MI, USA; Telephone No:+517-884-2053; Email: james.trosko@hc.msu.edu.

(c) 2018 Trosko JE. This article is distributed under the terms of the Creative Commons Attribution 4.0 International License

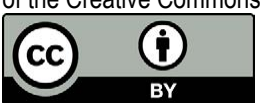

\section{Keywords}

Precision Medicine

Epigenetic mechanisms

Gap junctional Intercellular Communication

Pathogenesis of Cancer

Biological evolution

Cultural Evolution

Mutagenesis

Cytotoxicity

\section{ABSTRACT}

While the concept of "precision medicine" is not new, sophisticated technologies have led to a view that the data generated will provide individuals, physicians and public policy-makers with the information required to predict, intervene and protect against many diseases. However, without understanding of the underlying molecular mechanisms, such as the mutagenicity, cytotoxicity or epigenetic alterations, induced by agents to which a human has been exposed, and with pathogenic events, such as birth defects, cardiovascular disease, cancer, immune responses, and reproductive or neurological diseases, there will be no "precision". The aim of this "Commentary" is that, while mutations and cell death contribute to human diseases, including cancers, the toxicity of chemicals is primarily due to epigenetic effects on human organspecific adult stem cells. From the perspective of biological evolution, the transition from single- to multi-cellular organisms, along with the generation of new genes and cellular processes, led to the evolution of Homo sapiens and "cultural evolution". This transition has created a "collision" of the slow biological evolution of genes that are important for survival in various environments, with extremely fast cultural evolution. This has occurred when cultural evolution has provided new means of migration for both people and foods, as well as new methods of agriculture and food production/distribution/ processing. The population explosion, ecological alterations, global climate changes, and worldwide economic disparities all have a bearing on how the increases in median life span and the incidence of chronic metabolic diseases are managed in the face of globally limited healthcare resources.

"The existence of cellular communication at the local level is of tremendous importance in connection with the understanding of cell differentiation, the blocked ontogeny hypothesis of cancer development, the initiation-promotion concept, and the issue of the threshold for carcinogenic substances.

Intercellular communication results from molecular movement or contact between like or unlike cells. Molecular movement between cells can be categorized in simplest terms as local communication, affecting the microenvironment of cells that are within a volume encompassing relatively few cell diameters, and as systemic communication, in which the substances enter the blood stream and are widely distributed within the animal body ${ }^{1}$."

\section{Introduction: A Hypothesis-Driven Mechanistic or Empirically-Generated Data Mining Approach to Understanding the Pathogenesis of Human Diseases}

Since the advent of the scientific approach to understanding the workings of the natural world, two fundamental approaches have been championed by various scientists and examples can be 
presented to illustrate the success of each approach. In the case of the empirical approach, simple accumulation of large amounts of observational data might reveal a pattern that can be used to develop tangible practical applications, without ever knowing the underlying mechanism. On the other hand, hypothesizing specific mechanisms of action associated with a certain phenomenon could lead to solutions to practical problems.

In the general fields of the life sciences and human diseases, we are now entering the age of precision or personalized medicine ${ }^{2,3}$. While this is often viewed as a new era of research, precision medicine has been in common use since prescription glasses were designed to correct vision, the determination of blood types for blood transfusions and the identification of genes responsible for disorders such as phenylketonuria, albinism and xeroderma pigmentosum. These advances enabled physicians to develop either specialized therapies to prevent or to manage potential health problems. Determining the genetic basis of hereditary diseases, such as phenylketonuria, albinism or xeroderma pigmentosum and identifying the environmental triggers (the amino acid content of dietary proteins and exposure to ultraviolet (UV) light), has facilitated the prevention of the diseases associated with inheritance of those mutated genes. Out of this accumulated evidence, emerged the general concept that all human phenotypes are dependent on the interaction of genes and environmental factors defined as "nature and nurture", rather than "nature versus nurture".

Given the relatively-recent explosion of highly sophisticated molecular technologies, the concept of precision medicine has taken on a contemporary role as a support to the empirical approach, in that it is now possible to generate vast quantities of data on any disease. Data mining using the relatively new discipline of bioinformatics, which is based on the use of novel algorithms, seems to be "the order of the day". Currently, data mining is predominantly based on the assumption that the main drivers of highly complex human diseases, such as cancer, autism, Alzheimer's, and amyotrophic lateral sclerosis (ALS), are associated with variations in the primary genomic DNA codes. However, more recently, variations in the epigenetic alterations of the primary genomic information have been proposed as important influences ${ }^{5-8}$. In either case, the way forward seems to involve examining large datasets generated by various technologies with the aim of identifying variations or molecular epigenetic changes in the genomic DNA that are associated with any disease entity.

At this point in the history of the life sciences, we have now identified the "nature and nurture concept" as the foundation of any approach to understanding the mechanisms involved in disease pathogenesis. In addition, the cybernetic principle of feedback of signals between the environment and the genome is well known to affect health and disease ${ }^{9-11}$. Along with the additional philosophical "hierarchical" principle by with each level of the living system, from the atomic to the molecular, to the biochemical/cellular to the tissue/organ, to the physiological to the psycho-social-cultural levels, these concepts can be applied to help explain how diseases are influenced by all these factors.

Even more recently, evidence for the role of stem cells in normal development has been bolstered by the isolation of embryonic stem cells, induction of pluripotent stem cells, somatic nuclear transfer of reprogrammed pluripotent stem cells, and the isolation of organ-specific adult stem cells $s^{12-16}$. These stem cells represent new technological resources for either hypothesis-driven or empirically-generated data mining approaches to the investigation of human disease mechanisms $^{17-19}$.

\section{Clarification of the Pathogenesis of Any Human Disease is Based on Understanding the Mechanism of Toxicity}

There are only three mechanisms of toxicity that will contribute to the pathogenesis of any human disease, namely, mutagenesis, cytotoxicity, and alteration of nuclear genomic DNA by epigenetic change ${ }^{20}$. Thus, while the pathogenesis of cancer is very different to the mechanism responsible for a birth defect or the aging process/age-related diseases, such as Alzheimer's, one (or more) of these three basic mechanisms of toxicity must be involved.

\section{Gene and Chromosomal Mutagenesis}

It is now known that there are multiple molecular mechanisms by a point or chromosomal mutations occur. The errors in DNA repair that lead to conditions, such as the skin cancers seen in patients with xeroderma pigmentosum syndrome, are associated with the lack of repair of UV-induced pyrimidine dimers ${ }^{21-25}$. On the other hand, errors in DNA replication, such as those seen in Bloom's syndrome, are apparent after stimulation of replication of cells that are presumably, adult organspecific stem cells ${ }^{26,27}$.

Chromosomal mutations, such as chromosomal translocations, aberrant chromosome numbers, and chromosomal deletions or duplications, are the result of completely different underlying molecular mechanisms. As an example to illustrate this point, UV light is an effective point mutagen (as in the case of the xeroderma pigmentosum $)^{23,24}$, while ionizing radiation, a rather poor point mutagen, is an effective chromosomalmutagen $^{28}$. Thus, while both UV light and ionizing radiation are associated with human carcinogenesis, 
these factors contribute to the pathogenesis via very different mechanisms ${ }^{29}$.

\section{Cytotoxicities}

Cellular cytotoxicity can also occur via very different mechanisms. In general, necrosis occurs whenever a point or chromosomal mutation renders a critical component of a cell non-functional. As an example, genomic DNA damage caused by low-level UV light might be repairable; however, exposure to high levels of UV light might result in extensive DNA damage that swamps the repair system which, combined with non-repairable membrane damage, leads to necrosis.

Cell death can also be caused by non-mutagenic agents, such as alcohol. In this case, levels of alcohol above a particular threshold might cause disruption of the normal function of the cell membrane, leading to necrosis ${ }^{30}$. However, alterations in gene expression can lead to cell death by apoptosis ${ }^{31}$ or autophagy ${ }^{32}$. In other words, an agent that has the ability to alter gene expression, epigenetically, can lead to a unique kind of cell death. Cells exist in a three dimensional environment; therefore, when cells die, the surviving cells are stimulated to proliferate as a means of compensatory hyperplasia through tightly controlled feedback mechanisms involving extracellular signaling or gap junctional intercellular communication (GJIC) ${ }^{33}$. Only in tissues that have the capacity to perform compensatory hyperplasia, would one observe this response to massive cell death. Cell death-induced inflammatory responses can be triggered by the cellular debris resulting from necrosis, wound healing, or by cell removal during surgery ${ }^{34,35}$. As will be illustrated later in this commentary, cell death contributes indirectly to the promotion of the multi-state carcinogenic process ${ }^{36}$.

Cell death can be brought about by the other mechanisms of toxicity (i.e., mutagenesis and epigenetic alteration of gene expression). The potential effects on the pathogenesis of any particular disease depend on both the cell type and level of exposure. The human body comprises approximately 200 trillion cells ${ }^{37,38}$, with three basic types in each organ, namely, the relatively few organ-specific stem cells, their progenitor cells, and their terminally differentiated derivatives. Therefore, depending on the number or type of cell that is induced to die by cytotoxicity, there might be very different consequences, from almost no consequences to death of an embryo, to diseases in later life $^{39}$ or to the aging process itself ${ }^{40-42}$. This latter point seems to be illustrated by the inherited mutated lamin A gene associated with Hutchison- Gilford progeria syndrome ${ }^{43,44}$.

\section{Epigenetic Alteration of Gene Expression}

Clearly, a number of genes are collected in the genome during the evolution of multicellular species. However, as is simply illustrated by the development of a butterfly, specific sets of genes within the genome are expressed at each stage (genes enabling chewing during the larval stage; genes to remove the larval stage structures and functions during the pupal stage to prepare for new structures and functions of the butterfly wings and proboscis). The current explosion of concepts and technologies used to study epigenetic mechanisms focus almost entirely on monitoring methylation/ethylation changes in DNA or histone proteins and the enzymes that catalyze those changes at the DNA and intracellular biochemical levels ${ }^{45-47}$.

However, this approach does not consider the phenomenon of intercellular communication via quorum sensing that must exist during the transition of a single cell into a multicellular organism ${ }^{48}$. This transition is associated with the emergence of newgenes and phenotypes, such as (a) a low oxygen-micro-environment(i.e., niche ${ }^{49,50}$ ); (b) stem cells that divide either symmetrically or asymmetrically, depending on environmental signals ${ }^{51}$; (c) extracellular and extracellular adhesion molecules ${ }^{52}$; (d) gap junction or connexin family of genes ${ }^{53}$; (e) epigenetic molecular/ biochemical mechanisms that differentially regulate specific gene sets ${ }^{54}$; and (f) cell senescence ${ }^{55}$. Focusing only on changes in DNA regulation at the DNA or histone levels, without the conceptual view of the multicellular organism, is to ignore the penultimate upstream events that must take place prior to these downstream molecular/biochemical events. The basic hypothesis of this "commentary" is that, in a three-dimensional multi-cellular organism, such as a chordate metazoan, the various cells within and between tissues and organs must be in a homeostatic and cybernetic relationship via both extracellular and gap junctional intercellular signaling mechanisms ${ }^{56,57}$.

\section{Normal Metazoan Development Requires Precise Integration of Extracellular-, Intracellular- and Gap Junctional- Intercellular Communication Mechanisms}

Single cell organisms evolved and survived in an anoxic environment and generated energy for survival and reproduction via glycolysis of glucose. Thus, during the transition to multicellularity in an oxygenated environment, a change in the mechanism of energy production is required. This is achieved by the newly emerged genotypes and phenotypes, which allow adaptation of this new multicellular organism to generate more ATP by coupling of the symbiotic organelle, the mitochondria, in an oxygenated environment ${ }^{58-62}$.

The proliferation and intercellular adherence of the cells in this early multicellular organism are due to the ability of these cells to synthesize collagen-type molecules in an oxygen-dependent manner ${ }^{63,64}$. As the cells start to 
proliferate symmetrically, they produce a "ball" of adhering cells, all with equal access to the external and internal environments. The combination of signals from nutrients, oxygen and cell-cell contact induces the same signals from both extracellular and intracellular molecules. Invagination of this ball of cells creates an unequal microenvironment in this developing multicellular organism, such that there is differential net signaling within the various regions. This induces differential expression of genes in the total genomic information. In other words, cell differentiation leads to the production of different cell types, such as muscle cells, blood cells, heart cells, eye cells, neuronal cells, hepatic and kidney cells, which provide the multicellular organism with adaptive features in an ever-changing environment ${ }^{56}$. The highly complex development of metazoans was possible only due to the emergence of the connexin family of 20 highly evolutionarily-conserved genes encoding a membrane-associated organelle, the gap junction ${ }^{65}$. These proteins serve to integrate the extracellular and intracellular signals to modulate the opening or closing of channels to allow the passage of connexin-specific small regulatory ions/molecules ${ }^{66-68}$. The most important point that must be made here is that connexin gene expression and gap junction functions can be modulated at the transcriptional-, translational- and post-translational levels.

While there seems to be some disagreement about the idea $^{69}$, there is some direct evidence that, by virtue of their undifferentiated status, stem cells do not express their connexin genes or have functional gap junctions ${ }^{17}$. In other words, in the low oxygen microenvironment, stem cells remain undifferentiated, and are under growth control or in a state of quiescence induced by mitotic suppression of the niche extracellular matrix and soluble negative anti-mitotic signals. Only when either pro-mitotic signals or high levels of oxygen reach the stem cells in the niche, does the cell trigger mitochondriogenesis and connexin expression, as well as downregulation of the $0 c t 4 \mathrm{~A}^{57,70}$ and drug transporter genes to induce asymmetric division and differentiation of cells. These gap junctions have been shown to be associated with contact-inhibition or growth control and differentiation of stem cells ${ }^{71}$.

Stem cells (both germinal and somatic) can divide either symmetrically or asymmetrically, depending on oxygen concentrations ${ }^{72}$. During the evolution of a multicellular organism, co-evolution of other genes is required to protect the newly emerged stem cells against the low oxygen microenvironment and to protect the genomic DNA from damage caused by both external agents and internal metabolism of glucose via oxidative phosphorylation. Evolution of antioxidant and DNA repair mechanisms was also required. From an evolutionary point of view, the existence of multicellularity in an oxygenated environment required a mechanism that allowed the new stem cell, which had maintained many phenotypes for symmetrical cell division and non-differentiation, to exist in the multicellular organism as it did in the single cell organism. The low oxygen microenvironment of the niche within the oxygenated differentiated environment provided the conditions to maintain stem cell quiescence. This remarkable phenomenon involving the co-existence of two very different microenvironments could only occur through the precise homeostatic integration of a set of indirect soluble and direct gap junctional communication mechanisms.

\section{Role of the Disrupted Integration of Extracellular-, Intracellular-and Gap Junctional-Intercellular Communication on the Toxicities of Agents and their Pathogenic Consequences}

Theoretically, every gene in the genome is potentially mutable. Within the concept of integration of extracellular and intracellular signaling as well as GJIC, any gene that might alter the molecular identity of an extracellular signaling molecule, such as a hormone, growth factor or cytokine, or of a receptor or its intracellular signaling pathway, could regulate connexin gene expression or gap junction function ${ }^{73}$. Many human inherited diseases are associated with various connexin mutations ${ }^{74}$. While the number of these mutations and those affected in the human population might be considered small, the toxicological mechanism of mutagenesis that influences cell-cell communication remains to be elucidated.

However, disruption of the delicate homeostatic regulation of this integrated signaling system seems to be related to the mechanism of many cytotoxic agents. Depending on the timing and number of cells killed by non-mutagenic agents, the debris of these dying cells induces compensatory hyperplasia in the surviving cells via cytokines ${ }^{22}$. This has implications for the surviving cells that receive these death-associated molecular signals. For instance, there may be differential responses to these death-associated signals in a tissue with adult organspecific stem cells, their progenitors, and differentiated daughter cells. If the receptors, drug transporters, and expression of antioxidant or repair genes in these cell types are different, it can be speculated that the stem cells will be stimulated to divide symmetrically, while the progenitor cells will be induced to differentiate and the differentiated cells will respond adaptively.

In the case of apoptotic cell death, there seems to be a link to the epigenetic mechanism of cytotoxicity, in that, apoptosis induction might be related to the prevention of some diseases, whereas its inhibition seems to be associated with the promotion of tumors ${ }^{75,76}$. To date, a similar association with autophagy has not been identified. 
From a wider perspective, an insight into the important role of non-cytotoxic mechanisms of epigenetic toxicity in human diseases can be gained merely through internet searches of the association of modulation of gap junction function by non-mutagenic or non-cytotoxic agents with teratogenesis, tumor promotion, immune toxicology, reproductive and neurotoxicity. From retinoid-induced human birth defects ${ }^{77}$, through phorbol ester-induced tumor promotion ${ }^{78}$, to DDT-induced reproductive and neurological effects ${ }^{79}$, and the multi-toxic and preventive effects of thalidomide ${ }^{80-84}$, such searches reveal many well documented examples of how exposure to these chemicals at levels exceeding the specific threshold can either inhibit GJIC or prevent its inhibition by various agents ${ }^{85-87}$.

The molecular mechanisms underlying these epigenetic effects can occur via receptor-dependent and receptor-independent mechanisms. The effects of both endogenous and physiological chemicals, such as hormones, growth factors or cytokines, and exogenous agents, such as environmental toxins, toxicants, drugs, or food additives, are mediated through these epigenetic mechanisms. The receptor-dependent types seem to be related to concentration. For example, at physiological concentrations, estrogen inhibits the function of gap junctions and functions as a tumor promoter ${ }^{88}$. Yet, at receptor-independent, receptor saturation concentrations, it can also function as an anti-tumor promoter ${ }^{89,90}$. A possible interpretation of these observations could be that at physiological levels, binding to an estrogen receptor triggers a mitogenic signaling pathway, whereas, at higher concentrations, estrogen induces a receptor-independent signaling pathway that interferes with the mitogenic signaling through downregulation of GJIC. To further illustrate the potential of GJIC modulation of epigenetic toxicity and its role in carcinogenesis should serve to support its powerful role in human disease.

\section{Epigenetic Mechanism of Toxicity Via the Modulation of GJIC in Human Carcinogenesis}

Early observations by Werner Loewenstein ${ }^{91}$ represented the "Rosetta Stone" in developing the hypothesis that GJIC plays a major role in the toxicological mechanism of many human diseases ${ }^{92}$. It was well-known that cancer cells seemed to have lost the capacity for growth-inhibition or growth control ${ }^{93}$, as well their ability to terminally differentiate and gained "immortality" or lost the capacity for senesce ${ }^{94,95}$. While the cells in a tumor are both genotypically and phenotypically heterogeneous ${ }^{96}$, all tumors seem to have originated from a single target cell. In addition, while there still is no consensus on the origin of cancer cells (the "stem cell hypothesis" ${ }^{\text {"7-102 }}$ versus the "dedifferentiation or reprogrammed hypothesis" ${ }^{\prime 103}$ ), the new cancer stem cells are more likely to originate from a normal organ-specific adult stem cell ${ }^{57,104-109}$.
Loewenstein's observation that cancer cells lacked GJIC was linked to loss of growth control, inability to terminally differentiate, and the immortality of a somatic cell. While this association did not translate directly to causation, it paved the way for the hypothesis of its major role as a mechanism of toxicity in the pathogenesis of a multifactorial disease. At that time, there were at least two major unknowns concerning carcinogenesis. First, the concept of carcinogenesis as a multi-stage, multi-mechanism process, consisting of the initiation, promotion and progression phases, was only in just being formulated ${ }^{110-112}$. These were operational definitions of clearly distinct phases by which a single, "normal" cell could be made immortal by some agent that seemed to induce an irreversible event in that single cell. Furthermore, that single immortal or "initiated" cell could exist during an entire lifetime without becoming a metastatic tumor. Alternatively, the single initiating cell could be clonally amplified through exposure to agents or conditions that mediated escape from suppression either by the immune system, mitotic agents ${ }^{113}$, or apoptotic events ${ }^{76}$; this was defined as the tumor promotion phase. This exposure to epigenetic agents had to be sustained, regular, above threshold levels ${ }^{114-118}$, and in the absence of anti-promoter or antioxidant agents ${ }^{87,88}$. This promotion process was potentially interruptible or even reversible ${ }^{119}$.

Finally, during the long promotion process, additional epigenetic and genetic changes could push this initiating cell to become invasive and metastatic, achieving the socalled "hallmarks of cancer"93,94. These three phases of carcinogenesis, while being operationally-defined, have underlying mechanisms of toxicity.

Because the initiation step in a single cell appears to be irreversible, it has been generally assumed that this step is due to a mutagenic process. Today, we are aware that mutations can be induced in any gene by errors of DNA repair, as is illustrated by the inherited skin-cancer prone syndrome of xeroderma pigmentosum. By these cells having the defects in DNA repair of UV-induced in the skin cells, render individuals affected by this disorder at high risk of mutations in their skin cells, some of which will be associated with oncogenes ${ }^{22}$. On the other hand, mutations can also be formed by errors of DNA replication, as is seen in the hereditary cancer-prone Bloom's syndrome ${ }^{29}$. In this example, every time a stem cell is stimulated to proliferate, there is a finite chance of a mutation being formed during genomic DNA replication.

It is here that a radical hypothesis can be posited. Namely, while DNA damage induced by UV light can explain cancers in the very rare syndromes caused by errors in DNA repair, it is likely that chemicals associated with all kinds of cancers (lung, breast, prostate, liver, etc.) DO NOT INDUCE GENOMIC DNA DAMAGE OR CAUSE GENOMIC MUTATION. Rather, 
chemicals associated with carcinogenesis must function as tumor promoters by acting as mitogens and inhibitors of apoptosis, in pre-existing initiating stem cells. It is possible that these cancer-associated non-mutagenic or "epigenetic-acting" chemicals induce a genomic mutation in organ-specific adult stem cells simply by an error of DNA replication occurs during the stimulated cell proliferation.

If the promotion process acts by clonal expansion of a single initiated cell and prevention of its apoptotic death, there has to be a mechanistic basis for these biological cellular processes, as well as an explanation of the origin of the three types of cells in the organ; i.e., the organspecific stem cell, the finite life span progenitor cells and the terminally differentiated derivatives of that lineage.

One of the first hypotheses for the tumor promotion process was supported by the reversible inhibition of GJIC by phorbol esters, both in vitro ${ }^{78}$ and in vivo ${ }^{120}$. This observation enhanced the primary observation of Loewenstein that cancer cells lack functional GJIC. Furthermore, a number of endogenous chemicals, such as hormones, growth factors, cytokines ${ }^{120-125}$, and exogenous chemicals, such as pollutants, pesticides, food additives, and pharmaceuticals ${ }^{126,127}$, could inhibit GJIC and apoptosis and act as tumor promoters. In addition, various oncogenes, such as ras, raf, and $s r c$, inhibited GJIC stably, an effect that was reversed by a tumor suppressor gene ${ }^{84}$. When mutated connexin or gap junction genes were expressed in normal cells, they exhibited the characteristics of tumor cells ${ }^{128}$, whereas the normal phenotype was restored in unmodified connexin gene-transformed cancer cells ${ }^{129}$.

This model can be illustrated and provide support for this hypothesis by a re-interpretation of many examples, including that of cigarette smoke-induced lung cancers and environmental chemicals that induce oxidative stress, but not genomic mutations (DDT, TPA, phthalates, polybrominated and polychlorinated biphenols, bisphenol A, etc. $)^{130}$. In the case of cigarette smoke chemicals, we know that the number of cigarettes smoked, the length of time of regular smoking, secondary smoke exposure, smoking cessation and the interaction with other exogenous chemicals, such as green tea ${ }^{131}$, influence the frequency of lung cancers ${ }^{132}$. It is generally assumed that many cigarette smoke chemicals act by damaging genomic DNA and inducing mutations. However, some of the most predominant molecules in cigarette smoke include the small molecular weight polyaromatic hydrocarbons, such as methylanthracenes ${ }^{132}$, which can reversibly inhibit GJIC at concentrations above a threshold level and in the absence of an antioxidant ${ }^{133}$.

Using the new three-dimensional model to grow organoids, these chemicals, plus other cigarette-associated molecules, such as NNK and other in vivo tumor-promoting chemicals, such as TCDD, and bisphenol A, have been shown to cause cellular proliferation ${ }^{134,135}$, expression and selection of Oct4A gene-associated cells, to inhibit GJIC, and act as epigenetic tumor-promoting agents.

\section{Implications of Epigenetic Agents as Potential Toxins/ Toxicants}

To interpret and apply information about epigenetic chemicals, it must be remembered that both the endogenous chemicals, such as growth factors and hormones, and exogenous chemicals, such as DDT, TPA, and TCDD, can trigger signaling pathways that might, in fact, be identical, but which, nevertheless, modulate GJIC. On the other hand, if an epigenetic chemical interacts with stem cells, it could either stimulate proliferation ${ }^{136,137}$, or induce connexin gene expression and cause GJIC to induce cell differentiation or apoptosis, as in the case of genistein ${ }^{138}$.

To put this idea into perspective, from conception to maturation, the multicellular organism has a dynamic homeostatic system of extracellular signaling between all the stem cells (embryonic and organ-specific adult) and their terminally differentiated progeny, in addition to signals from other organs. Furthermore, normal adult and initiated organ-specific stem cells can be targeted by these epigenetic agents. The normal stem cells might have limited proliferative potential in response to these epigenetic chemicals, whereas the initiated stem cells, which cannot undergo terminal differentiation or divide asymmetrically, would continue to proliferate by symmetrical cell division ${ }^{56}$.

It should be apparent that altering the ability of embryonic/early fetal or specific adult stem cells to divide symmetrically or asymmetrically could lead to either embryonic/fetal lethality or to teratogenesis. Moreover, altered stem cell behavior during critical periods of development in a certain organ, such as the brain, could lead to the later development of conditions appearing later in life, such as autism, schizophrenia, and bipolar disorder or various childhood brain cancers ${ }^{139}$.

\section{Microbiological Agents, Stem Cell and Cell-Cell Communication}

While most of this discussion of epigenetic agents centers on endogenous or exogenous chemicals, one must also consider various biological entities, such as parasites, microbial or viral agents. Many of these biological agents are seen as infectious entities associated with acute and chronic inflammatory diseases. Chronic inflammation has now been linked to many metabolic diseases, such as diabetes, cardiovascular diseases, cancer, and dementia ${ }^{140-144}$ and there has been an explosion of linkages reported between gut microbiota with many chronic diseases ${ }^{145-147}$. Even the classic Chagas disease, which was recognized as one of Darwin's maladies after his famous trip on the Beagle ${ }^{148}$, has 
been linked to a parasite that affects GJIC in heart cells ${ }^{149}$. The link between inflammation, many chronic diseases, GJIC, microbiological organisms and various environmental pollutants, medications, and dietary chemicals have to be viewed in a systems fashion ${ }^{150,151}$.

However, identification of the link between various viruses and human cancers, for which Dr. Harald zur Hausen was awarded the Nobel Prize ${ }^{152}$, still seems to escape clear explanation as to how various viruses, such as hepatitis, human papilloma virus (HPV), and SV40 virus, might cause cancer. However, if all cancers, with the exception of teratomas, are caused by the "initiation, promotion, and progression" mechanism and fit into the stem cell hypothesis of cancer, there might be a simple explanation. An explanation emerged only when it was shown that radiation and various chemical carcinogens could not transform normal human fibroblasts or epithelial cells from the state of mortality to immortality ${ }^{153-155}$, while various viruses, such as SV40 and HPV, could transform a few normal, mortal cells in human primary cultures into immortal, but not, tumorigenic cells ${ }^{156,157}$. Early primary cultures of any human tissue would be expected to contain a few organ-specific adult stem cells. Therefore, it can be hypothesized that the viruses used to transform these cells might infect both the major population of somatic differentiated cells with limited proliferative capacity (or mortal cells), as well as the few organ specific stem cells, which are, by definition, immortal until induced to terminally differentiate. Some might interpret the survival of a few immortalized cells to be the result of the ability of these viruses to reprogram the few somatic differentiated mortal cells or mutate the genome of these cells so they become immortal. However, an alternative explanation is that these viruses block the differentiation or apoptosis of the few organ-specific stem cells, but have no effect on the somatic differentiated cells which ultimately died during "crisis". Only these few adult organ-specific stem cells infected with the virus grew and remained immortal. In other words, these so-called "immortalizing viruses" are not really capable of immortalizing the mortal cells, but rather they block mortalization of immortal stem cells. Once differentiation is prevented, these adult stem cells can live long enough to become neoplastically transformed by radiation, other chemicals or oncogenes. This phenomenon was first demonstrated in vitro by Land et al. ${ }^{158}$, and later confirmed directly in human adult breast stem cells infected with the SV40 virus ${ }^{159}$.

The recent demonstration of the anti-cancer effects of prevention of infection by cancer-associated viruses, such as HPV and hepatitis ${ }^{160-161}$, indicates the possibility that proactive intervention with antivirus therapies at a young age lowers the risk of adult organ-specific stem cell initiation. Without adult organ-specific initiated stem cells, there cannot be a high risk that cancers could arise from non-initiated adult stem cells.

\section{Good News/Bad News of Chemicals that Modulate Cell-Cell Communication}

One feature associated with many epigenetic toxicants or chemo preventive agents is the balance between oxidative stress and antioxidant factors ${ }^{54}$. Many of these specific chemicals can function as an antioxidant under one set of conditions and a pro-oxidant under another set ${ }^{162}$.

The retinoids and thalidomide are classic examples of epigenetic toxicants that can have either beneficial or detrimental consequences on health. Retinoids have been shown to function as either tumor promoters or antitumor promoters ${ }^{163,164}$. Thalidomide, which was produced as a sedative, was shown to be a human teratogen ${ }^{81}$ but has also been used as to treat leprosy ${ }^{83}$ and more recently, is being used as an anti-angiogenic cancer treatment ${ }^{80}$. The underlying mechanism in each case appears to be associated with the ability for $\mathrm{GJIC}^{82}$. Therefore, while highly complex in their use, the particular physiological circumstances of the use of such agents in terms of the stage of development, when the chemical could lead to teratogenesis or during the onset of a disease, when it might provide some protection against the pathogenesis of a condition, such as anxiety, leprosy or cancer must be understood. This, then, poses a major dilemma to regulators who must assign a causation or risk factor to the use or non-use of such agents, or to the specific conditions of their use. In effect, the task of governmental regulatory agencies is to protect the public from potential harm caused by the use of agents that might have some practical benefit. This is made extremely difficult by the wide spectrum of values and the need for a basic scientific understanding. Every human decision is based on a combination of established information and personal values ${ }^{165}$ rendering it impossible to arrive at a generally-accepted or universal conclusion on use or nonuse in the highly complex multi-cultural societies of today. At best, "facts" are always based on incomplete information and at worst, they can be wrong. However, scientific "facts" can be "upgraded" on the basis of new findings. Personal values are not absolute, but experientially accepted, and especially influenced by cultural factors. Consequently, human decision making both at the level of the individual and regulatory agencies is extremely complicated. The risk/benefit concept is not based on two equally weighted absolutes, but on two equally fluid variables. Should I have a "right" to take thalidomide to treat my cancer, since I will not be pregnant (I'm a male) or should a female, who has an anxiety-related condition and may or may not be pregnant, be allowed to take the drug? Clearly, a more informed decision can be made with the availability of scientific evidence for the mechanism by which thalidomide works. This has to be weighed against the various values of 
the individual concerning, in this case, the possibility of disrupted fetal development during pregnancy and therefore, creating the need to make a decision based on attitudes to having a child with a serious birth defect or having an abortion.

In making these kinds of decisions, it is important to determine the potential toxicity of any agent that enters the body and its interaction with other exogenous agents (other drugs, food components, pollutants, their concentrations, microbiome influence, etc.) and episodic endogenous agents (hormones, growth factors, cytokines, etc.) that vary (during the day, stage of development, exercise, genetics, sex, etc.). In other words, elucidation of the mechanism of action of an agent ex-vivo (mutagenicity, cytotoxicity or epigenetic alteration of gene expression) reveals only one small aspect of that role of the agent in disease pathogenesis. Knowing that DDT is not mutagenic or not even cytotoxic at the concentrations to which most humans are exposed, and even knowing the average concentrations and frequencies of exposure that might alter gene expression, cannot be translated into an understanding of how the other exogenous and endogenous agents might interact in an additive, antagonistic or synergistic manner on some of the cells leading to pathology. Two individuals, even identical twins, might experience very different physiological and biological/pathological consequences to the exact same exposure to DDT. While the simple answer to this complex situation is merely to eliminate the agent from human exposure that solution might not yield the best health effect if there is no less harmful solution to the problem for which the agent is used and if its elimination might lead to much more human suffering.

Decision-making is an inherent problem of this complex human situation. The human body responds to immediate positive and negative feedback signals stimulated by exposure to the consequences of our decision. In many cases, the possible short-term reaction to our decision might be that we are either unaware of the negative effects of that feedback or even, with our ability to predict longterm consequences of this action, we make the decision based on some short-term positive effects.

Today, we are now experiencing a global metabolic disease crisis. On a larger global scale, the median life span is generally increasing, due in part to decreasing infant mortality, better sanitation, and decreasing incidence of infectious diseases. The flip-side to this "good news", is the increased chance of experiencing chronic diseases, such as diabetes, cardiovascular diseases, cancers and dementia. Is this the result of "effluence of our affluence"? Of course, few would eliminate the knowledge that led to the better sanitation, nutrition, agricultural practices, medicines and public health policies resulting in improved infant mortality and a reduction in the threat of infectious agents and famine. As a consequence, we now have to deal with major global chronic disease problems, such as diabetes and the depletion of the limited healthcare resources that are required to manage the multiple disease sequelae of this condition. Moreover, there are the tragic effects of the increasing prevalence of various forms of dementia, such as Alzheimer's disease, on the affected individual, their family, and the limited global healthcare resources.

The contribution of early life influences on the risk of these chronic diseases remains to be determined.

The validity of the Barker hypothesis that early life exposure can lead to disease pathologies later in life ${ }^{166}$ seems to be a legitimate question to pose to the scientific community, as well as to the political and religious leaders of the world. In spite of the rather optimistic prediction of a few ${ }^{167}$, the scientific mechanisms underlying the current collision of biological and cultural evolutionary forces must be acknowledged, in terms of the fundamental fact of the human condition that we are all going to die. However, with the aid of improved healthcare, we do have now have the choice of an acceptable, less painful death over a miserable survival until death in its absence ${ }^{168,169}$.

\section{Conclusions: Broad Implications of a Complex Integrative View of how Toxic Agents Affect Human Health}

It must be acknowledged that there is no universal acceptance of all the concepts and interpretation of experimental data. Nevertheless, without an attempt to formulate a view of how toxicological mechanisms could affect the pathogenesis of human disorders, including, birth defects, cardiovascular diseases, diabetes, and cancers, as well as aberrant immunological reactions and reproductive and neurological dysfunction, little progress will be made. This commentary provides a cautious, but well documented, interpretation of how radiation, chemicals, and biological entities might contribute to these disorders.

First, the list of basic assumptions includes the concept that gene and environmental interactions ("nature and nurture", not "nature versus nurture") must be the predominant framework that can be used to explain all diseases. Second, mutations, either inherited or somatically-acquired, at the gene or chromosomal level, can occur via errors of DNA repair or errors of DNA replication. Third, while UV radiation is a highly efficient point mutagen causing errors of DNA repair, ionizing radiation is a rather poor point mutagen, although chromosomal mutations are introduced at high doses. Point mutations can be caused by errors of DNA replication whenever cells replicate. Fourth, these mutations caused by errors of DNA replication in stem cells are associated with a greater risk of leading to some pathologies, such as cancers, while those mutations that occur in limited replicating, non-stem cells, 
or terminally differentiated cells will not lead to diseases such as cancer. Fifth, agents that can cause cytotoxicity can have multiple consequences in the pathogenesis of diseases depending on the dose/concentration of the agent, the stage of development, sex, and cell type affected (stem versus terminally differentiated). Sixth, agents that induce epigenetic alteration of gene expression can be of endogenous or exogenous origin and their biological consequences depend on exceeding the threshold exposure level, the cell type affected, (e.g., normal or initiated stem cells versus non-stem cells), the stage of development, and sex, in addition to the timing and duration of uninterrupted exposure in the absence of agents that inhibit the action of these epigenetic agents. Seventh, these epigenetic agents, both endogenous and exogenous, can induce receptordependent and receptor-independent intracellular signaling pathways, which might be identical. Eighth, these epigenetic mechanisms can occur at either non-cytotoxic or cytotoxic levels to influence both inflammatory cells and the stromal/ epithelial cells, within and between human tissues. Ninth, importantly, when an agent enters the body, it targets multiple organ systems and immune and non-immune cells, which in turn, induce the production of secreted chemicals that can interact with the other affected cells.

Probably, the major assumption to be made concerning the toxicities of chemicals is that, while many can induce oxidative stress and reactive species, those chemicals associated with some pathologies (birth defects, cancer, atherosclerosis, Parkinson's disease. etc.) are most likely to induce cytotoxicity at very high concentrations or epigenetic alteration of gene expression at non-cytotoxic levels, primarily in organ specific adult stem cells. In addition, some chemicals, such as thalidomide, can have either beneficial or detrimental effects depending on the specific conditions of exposure and use.

Because of the "Queen Bee" characteristics of embryonic and organ-specific adult stem cells, alterations in their numbers (increased or decreased) induced by toxic agents (mutagenic, cytotoxic, or epigenetic), particularly during early development, could have major consequences later in life (the Barker hypothesis). Thus, in the case of any disease that depends on stem cell origin or stem cell homeostasis, genes that affect stemness, such as Oct $4 \mathrm{~A}^{170-173}$, should be monitored to improve our understanding of the mechanism by which any toxic agent might contribute to the pathogenesis.

Lastly, if one accepts that toxic chemicals can act via epigenetic mechanisms, it must be considered that in vivo, cells exist in a three-dimensional milieu and are influenced by extracellular communication via extracellular matrices, cell-cell adherent molecules, and extracellular soluble molecules together with either a low oxygen microenvironment provided for the stem cells by a niche or by GJIC and hemichannels. Modulation of these two mitotically-suppressing systems can trigger mitogenic effects, differentiation or apoptotic/autophagic consequences. While the current efforts to study epigenetic toxicities have focused on the late downstream effects on DNA and protein methylation in the nucleus, it is actually the upstream effects of these epigenetic agents on extracellular and GJIC that should be monitored. Therefore, cells can exist, with or without expression of their connexin or gap junction genes, although their non-function can be mitigated either by mutations or by the rendering them non-functional due to oncogene modification.

In summary, it was the evolutionary emergence of the stem cell and mechanisms underlying the homeostatic regulation of cell proliferation, cell differentiation, apoptosis, and senescence by the family of the connexin or gap junction genes that led to multicellularity of the humans. These evolutionary factors should form the main conceptual framework that helps to clarify the mechanisms of toxicity influencing the pathologies of many, if not, most human diseases. In addition, while mutations and various forms of cell death can and do play a role in human diseases, endogenous and exogenous chemicals, associated with the onset of diseases, act via mechanisms of non-mutagenic and non-cytotoxic epigenetic alteration of gene expression, particularly in adult organ-specific stem cells.

\section{References}

1. Potter VR. Cancer as a problem in intercellular communication: Regulation by growth -inhibiting factors (Chalones). Progress in Nucleic Acid Research and Molecular Biology. Vol. 29, pg. 162. W. E. Cohn, ed., Academic Press, New York, 1983.

2. Chen JC, Alvarez MJ, Talos F, et al. Identification of Causal Genetic Drivers of Human Disease through Systems Level Analysis of Regulatory Networks. Cell. 2014; 159(2): 402-414.

3. Lu YF, Goldstein DB, Angrist M, et al. Personalized medicine and human genetic diversity. Cold Spring Harb Perspect Med. 2014; 4(9): a008581. DOI: $10.1101 /$ cshperspect.a008581.

4. Chakravarti A, Little P. Nature, nurture and human disease. Nature. 2003; 23: 412-414.

5. Trosko JE, Chang CC, Madhukar BV, S.Y. Oh SY. Modulators of gap junction function: The scientific basis of epigenetic toxicology". In Vitro Toxicology. 1990; 3: 9-26.

6. Trosko JE. Precision Medicine for Childhood Cancers: Role of Epigenetics in Childhood Cancers". EC Paediatrics. 2017; 6 (1): 11-20.

7. Trosko JE. Commentary: Environmental Medicine: The Role of Epigenetic Mechanisms. SM J Pediatr. 2017; 2(2): 1011.

8. Portela A, Esteller M. Epigenetic modifications and human disease. Nature Biotechnology. 2010; 28: 1057-1068; doi:10.1038/nbt.1685.

9. Trosko JE. Hierarchical and cybernetic nature of biologic systems and their relevance to homeostatic adaptation to low-level exposures to oxidative stress-inducing agents. Environ. Health Perspect. 1998; 106: 331-339.

10. Brody H. A systems view of man: implications for medicine, science and ethics. Perspectives in Biology and Medicine. 1973; 17: 71-92.

11. Potter VR. The probabilistic aspects of the human cybernetic medicine, Perspectives in Biology and Medicine. 1974; 17: 164-183. 
12. Tompson JA, Itskovitz-Eldor J, Shapiro SS, et al. Embryonic stem cell 500 lines derived from human blastocysts. Science. 1998; 282: 1145-1147.

13. Shamblott MJ, Axelman J, Wang SP, et al. Derivation of pluripotent stem cells from cultured human primordial germ cells. Proc Natl Acad Sci USA. 1998; 95: 13726-13731.

14. Takahashi K, Yamanaka S. Induction of pluripotent stem cells from mouse embryonic and adult fibroblast cultures by defined factors. Cell. 2006; 126: 663-676.

15. Tachibana $M$, Amato $P$, Sparman $M$, et al. Human embryonic stem cells derived by somatic cell nuclear transfer. Cell. 2013; 153(6): 1228-38. 10.1016/j.cell.2013.05.006.

16. Trosko JE, Chang CC, Wilson MR, et al. Gap junction and the regulation of cellular functions of stem cells during development and differentiation. Methods. 2000; 20: 245-264.

17. Trosko JE. Mechanistic based 3-dimensional use of human adult stem cells in toxicology. Toxicological Sciences. 165(1), 6-9, 2018.

18. Taniya T, Tanaka S, Yamaguchi- Kabata Y, et al. A prioritization analysis of disease association by data-mining of functional annotation of human genes. Genomics. 2012; 99 (1): 1-9.

19. Iddamalgoda L, Das PS, Aponso A, et al. Data Mining and Pattern Recognition Models for Identifying Inherited Diseases: Challenges and Implications. Front Genet. 2016; 7: 136. doi: 10.3389/ fgene.2016.00136

20. TroskoJE. Reflections on the use of 10 IARC carcinogenic characteristics for an objective approach to identifying and organizing results from certain mechanistic studies. Toxicology Res. And Applications. 2017; 1: 1-10; DOl: $10.1177 / 2397847317710837$.

21. Cleaver JE. Xeroderma pigmentosum: genetic and environmental influences in skin carcinogenesis. J Dermatol. 1978; 17: 435-444.

22. Cleaver JE, Trosko JE. Absence of excision of ultraviolet induced cyclobutane dimers in Xeroderma pigmentosum. Photochem Photobiol. 1970; 11: 547-550.

23. Maher VM, McCormick JJ. Effect of DNA repair on the cytotoxicity and mutagenicity of UV irradiation and of chemical carcinogens in normal and xeroderma pigmentosum cells. In: Yuhas JM, Tennant RW and Regan JD (eds.) Biology of Radiation Carcinogenesis. New York: Raven Press, pp. 129145, 1976

24. Glover TW, Chang CC, Trosko JE, et al. Ultraviolet light induction of diphtheria toxin resistant mutations in normal and xeroderma pigmentosum human fibroblasts. Proc Natl Acad Sci USA. 1979; 76: 3982-3986.

25. Brash DE, Rudolph JE, Simon JA. A role for sunlight in skin cancer: UV induced p53 mutations in squamous cell carcinomas. Proc Natl Acad Sci USA. 1991; 88: 10124-1018.

26. German J. Bloom syndrome: a mendelian protype: somatic mutations and disease. Medicine. 1993; 72: 393-406.

27. Warren S, Schultz RA, Chang CC. Elevated spontaneous mutation rate in bloom syndrome fibroblasts. Proc Natl Acad Sci USA. 1981; 78: 3133-3137.

28. Wolff S. Radiation effects as measured by chromosome damage. In: Cellular Radiation Biology, Williams and Wilkins Co., Baltimore. pp. 167-183, 1965.

29. Trosko JE, Suzuki K. "Adult stem cells, the Barker Hypothesis, epigenetic events and low level radiation effects". In: Radiation Health Risk Sciences. Nakashima M, Takamura N, Tsukasaki K, Nagayama Y, Yamashita S, eds., Springer Publisher, Tokyo, pp.216-226, 2009.

30. Gu S, Nguyen BN, Rao S, et al. Alcohol, stem cells and cancer. Genes\& Cancer. 2017; 8(9-10): 695-700

31. Paschall AV, Liu K. Epigenetic regulation of apoptosis and cell cycle regulatory genes in human colon carcinoma cells. Genom Data. 2015; 5: 189-191. doi: 10.1016/j.gdata.2015.05.043

32. An PN T, Shimaji K, Tanaka R, et al. Epigenetic regulation of starvationinduced autophagy in Drosophila by histone methyltransferase G9a. Scientific Reports. 2017; 7, Article \# 7343 ; doi:10.1038/s41598-01707566-1

33. Argyris TS. Regeneration and the mechanism of epidermal tumor promotion. CRC Crit Rev Toxicol 1985; 14: 211-258

34. Trosko JE, Tai MH. Adult stem cell theory of the multistage, multimechanism theory of carcinogenesis: Role of Inflammation on the promotion of initiated stem cells". In: Dittmar T, Zaenker KS and Schmidt A (eds.) Infection and Inflammation: Impacts on Oncogenesis, Basel: Karger. Pp. 45-64, 2006. 35.

35. Rock KL, Kono H. The inflammatory response to cell death. Annu Rev Pathol. 2008; 3: 99-126.

36. Trosko JE. Is the concept of 'tumor promotion' a useful paradigm? Molecular Carcinogenesis. 2001; 30: 131-137.

37. Sender R, Fuchs S, Milo R. Revised Estimates for the Number of Human and Bacteria Cells in the Body. PLoS Biol 14(8): e1002533. doi:10.1371/journal.pbio.1002533

38. Bianconi E, Piovesan A, Facchin F, et al. An estimation of the number of cells in the human body. Ann Hum Biol. 49(6): 463-71.

39. Barker DJ. The developmental origins of adult disease. J Am Coll Nutr. 2004; 236: 588s-595s.

40. Trosko JE. Human stem cells as targets for the aging and diseases of aging processes. Medical Hypo. 2003; 60: 439-447.

41. Trosko JE. Aging as the 'Systems' breakdown of communication between the quality and quantity of stem cells. In: The Manefesto for a Long Life IL Manifesto Della Lunga Vita. Marandola, P. \& Marotta, F., eds., Sperling \& Kupfer Editori S.p.A, Milan, Italy, pp. 58-62, 2007.

42. Trosko JE. Role of diet and nutrition on the alteration of the quality and quantity of stem cells in human aging and the diseases of aging. Curr Pharm Des. 2008; 14: 2707- 2718.

43. Broers JL, Ramaekers FC, Bonne, G, et al. Nuclear lamins: Laminopathies and their role premature aging. Physiol Rev. 2006; 86:967-1008.

44. Scaffidi P, Misteli T. Lamin A-dependent nuclear defects in aging. Science. 2006; 312: 1059-1063.

45. Jones PA, Takai D. The Role of DNA Methylation in Mammalian Epigenetic. Science 2001; 293 (5532): 1068-1070; DOI: 10.1126/ science.1063852

46. Zhang Y, Reinberg D. Transcription regulation by histone methylation: interplay between different covalent modifications of the core histone tails. Genes \& Dev. 2001; 15: 2343-2360.

47. Rice JC, Allis CD. Histone methylation versus histone acetylation: new insights into epigenetic regulation. Curr Opin Cell Biol. 2001; 13(3): 263-73.

48. Miller M, Bassler BL. Quorum sensing in bacteria. Ann Rev Microbiol. 2001; 55: 165-199.

49. Fuchs E, Tumbar T, Guasch G. Socializing with the neighbors: stem cells and their niche. Cell. 2004; 116: 769-778.

50. Csete M. Oxygen in the cultivation of stem cells. Ann NY Acad Sci. 2005; 1049: 1-8.

51. Knoblich A. Mechanisms of Asymmetric Stem Cell Division. Cell. 2008; 132(4): 583-597; https://doi.org/10.1016/j.cell.2008.02.007.

52. Plopper G. The extracellular matrix and cell adhesion. In: Lewin B, Cassimeris L, Lingappa V, Plopper G, editors. Cells. Sudbury, MA: Jones and Bartlett. 2007. ISBN 0-7637-3905-7. 
53. Cruciani V, Mikalsen SO. The connexin gene family in mammals. Biol Chem. 2005; 386: 325-32.

54. Upham BL, Trosko JE. Carcinogenic tumor promotion, induced oxidative stress signaling, modulated gap junction function and altered gene expression". Antioxidation Redox Signaling. 2009; 11: 297-30.

55. Hayflick L. The limited in vitro lifespan of human diploid cell strains. Exp Cell Res. 1965; 37(3): 614-36.

56. Trosko JE. Evolution of microbial quorum sensing to human global quorum sensing: An insight to how gap junctional intercellular communication might be linked to global metabolic disease crisis. Biology. 2016; 5: 29 .

57. Trosko JE. A conceptual integration of extra-, intra-, and Gap junctional inter-Cellular communication in the evolution of multicellularity and stem cells: How disrupted cell-cell communication during development can affect diseases later in life. Internatl. J. Stem Cell Research \& Therapy. 2016; 3: 1-6; ISSN: 2469-570X.

58. Trosko JE, Kang KS. Evolution of energy metabolism, stem cells and cancer stem cells: how the Warburg and Barker hypotheses might be linked. Int J Stem Cells. 2012; 5: 39-56.

59. Nesti C, Pasquali L, Vaglini F, et al. The role of mitochondria in stem cell biology. Biosci Rep. 2007; 27(1-3): 165-71.

60. Armstrong L, Tilgner K, Saretzki G, et al. Human induced pluripotent stem cell lines show stress defense mechanisms and mitochondrial regulation similar to those of human embryonic stem cells. Stem Cells. 2010; 28(4): 661-73.

61. Prigione A, Fauler B, Lurz R, et al. The senescence-related mitochondrial/oxidative stress pathway is repressed in human induced pluripotent stem cells. Stem Cells. 2010; 28(4): 721-33.

62. Vander Heiden MG, Cantley LC, Thompson CB. Understanding the Warburg effect: the metabolic requirements of cell proliferation. Science. 2009; 324: 1029-33.

63. Saul JM. Did detoxification processes cause complex life to emerge. Lethaia. 2008; 42: 179-184.

64. Nursal JR. Oxygen as prerequisite to the origin of metazoan. Nature. 1959; 183: 1170-1172.

65. Revel JP. The oldest multicellular animal and its junctions. In Gap Junction; Hertzberg, E.L., Johnson, R., Eds.; Alan Liss, Inc.: New York, NY, USA. pp. 135-149 1988.

66. Cruciani V, Mikalsen SO. The connexin gene family in mammals. Biol Chem. 2005; 386: 325-332. 67.

67. Evans W H, Martin PEM. Gap junctions: structure and function. Mol Membr Biol. 2002; 19: 121- 136.

68. Aasen T, Mesnil M, Naus CC, et al. Gap junctions and cancer: communicating for 50 years. Nature Reviews Cancer. 2016; 16: 775788.

69. Wong RC, Pébay A, Nguyen LT, et al. Presence of functional gap junctions in human embryonic stem cells. Stem Cells. 2004; 22(6): 883-889.

70. Trosko JE, Chang CC, Wilson MR, et al. Gap junction and the regulation of cellular functions of stem cells during development and differentiation. Methods. 2000; 20: 245-264.

71. Loewenstein WR, Kanno, Y. Intercellular communication and the control of tissue growth: lack of communication between cancer cells. Nature. 1966; 209: 1248-1249.

72. Mohyeldin A, Garzón-Muvdi T, Quiñones-HinojosaA. Oxygen in Stem Cell Biology: A Critical Component of the Stem Cell Niche. Cell Stem Cell. 2017; 7 (2): 150-161.

73. Trosko JE. Chang CC. Factors to consider in the use of stem cells for pharmaceutic drug development and for chemical safety assessment. Toxicology. 2010; 270: 18-34.

74. Sninvas M, Verselis VK, White TW. Human diseases associated with connexin mutations. Biochim.Biophysic Acta (BBA)-Biomembranes. 2018; 1860 (1); 192-201.

75. Schulte-Hermann R, Grasl-Kraupp B, Bursch W. Dose-response and threshold effects in cytotoxicity and apoptosis. Mutat Res. 2000; 3; 464(1): 13-8.

76. Wilson MR, Close T, Trosko JE. Cell population dynamics, apoptosis, mitosis and cell-cell communication) during disruption of homeostasis. Exp Cell Res. 2000; 254: 257-268.

77. Accutane (Isotretinoin) and Other Retinoids. March of Dimes. 2008; http://www.marchofdimes.com/professionals/14332_1168.asp. Accessed 4/9/2010.

78. Yotti LP, Trosko JE, Chang CC. Elimination of metabolic cooperation in Chinese hamster cells by a tumor promoter. Science. 1979; 206.1089: 1091-1093.

79. Tsushimoto G, Trosko JE, Chang CC, et al. Cytotoxic, mutagenic and tumor promoting properties of DDT, Lindane and Chlordane on Chinese hamster cells in vitro". Arch Env Cont Toxicol. 1983; 12: 721- 730.

80. D’ Amato RJ, Loughnan MS, Flynn E, et al. Thalidomide is.an inhibitor of angiogenesis. Proc Natl Acad Sci USA. 1994; 91: 4082-4085.

81. Manson JM. Teratogenicity. In: Cassarett and Doull's Toxicology: The Basic Science of Poisons, 3rd ed. New York: MacMillan Publishing Co, 1986.

82. Nicolai S, Sies H, Stahl W. Stimulation of gap junctional intercellular communication by thalidomide and thalidomide analogs in human skin fibroblasts. Biochem Pharmacol 1997; 53: 1553-1557.

83. Teo S, Resztak KE, Scheffler MA, et al. Thalidomide in the treatment of leprosy. Microbes Infect 2002; 11: 1193-1202.

84. Vargesson N. Thalidomide-induced teratogenesis: History and mechanisms. Birth Defects Res C Embryo Today. 2015; 105: 140-156.

85. Trosko JE, Ruch RJ. Cell-cell communication in carcinogenesis. Front. Biosci. 1998; 3: 208-236.

86. Trosko JE, Ruch R. Gap junctions as targets for cancer chemoprevention and chemotherapy. Curr Drug Targets. 2002; 203: 465-482.

87. Leone A, Longo C, Trosko JE. The chemopreventive role of dietary phytochemicals through gap junctional intercellular communication. Phytochem Rev. 2012; 11: 285-307. DOI: 10.1007/s11101-0129235-7.

88. Chung TH, Wang SM, Wu JC. $17 \beta$-estradiol reduces the effect of metabolic inhibition on gap junction intercellular communication in rat cardiomyocytes via the estrogen receptor. Journal of Molecular and Cellular Cardiology. 2004; 37(5): 1013-1022.

89. Firestone GL, Bhumika J. Kapadia BJ, et al. Minireview: Regulation of Gap Junction Dynamics by Nuclear Hormone Receptors and Their Ligands. Mol Endocrinol. 2012; 26(11): 1798-1807. DOI: 10.1210/ me.2012-1065.

90. Leslie G, Ford LG. Paradoxical clinical effect of estrogen on breast cancer risk: a "new" biology of estrogen-induced apoptosis. Cancer Prev Res. 2011; 4(5): 633-637.

91. Loewenstein WR. Permeability of membrane junctions. Ann N Y Acad Sci. 1966; 137: 441-472.

92. Trosko JE. Gap junction intercellular communication as a 'Biological Rosetta Stone' in understanding, in a Systems manner, stem cell behavior, mechanisms of epigenetic toxicology, chemoprevention and chemotherapy". J Membr Biol. 2007; 218: 93-100.

93. Borek C, Sachs, L. The difference in contact inhibition of cell replication between normal cells and cells transformed by different carcinogens. Proc Natl Acad Sci USA. 1966; 56: 1705-1711. 
94. Hanahan D, Weinberg RA. The hallmarks of cancer. Cell. 2000; 100: 57-70.

95. Hanahan D, Weinberg RA. Hallmarks of cancer: The next generation. Cell. 2011; 144: 646-674.

96. Morii E. Heterogeneity of tumor cells in terms of cancer-initiating cells. J Toxicol Pathol. 2017; 30(1): 1-6. DOI: 10.1293/tox.2016-0056.

97. Markert CL. Neoplasia: A disease of cell differentiation. Cancer Res. 1968; 28: 1908-1914.

98. Pierce GB. Neoplasms, differentiation and mutations. Am Pathol. 1974; 77: 103-118.

99. Fialkow PJ. Clonal origin of human tumors. Ann. Rev. Med. 1976; 30: 135-176.

100. Potter VR. Phenotypic diversity in experimental hepatomas: The concept of partially blocked ontogeny. Br J Cancer. 1978; 1: 1-23.

101. Till JE. Stem cells in differentiation and neoplasia. J Cell Physiol Suppl. 1982; 1: 3-11.

102. Tai MH, Chang CC, Kiupel M, et al. Oct-4 expression in adult stem cells: evidence in support of the stem cell theory of carcinogenesis. Carcinog. 2005; 26: 495-502.

103. Sell S. Cellular origin of cancer: Differentiation of stem cell maturation arrest. Environmental Health Perspectives. 1993; 101(5): 15-26.

104. Trosko JE. From adult stem cells to cancer stem cells: Oct-4 gene, Cell-Cell Communication, and Hormones during tumor promotion. Ann NY Acad Sci. 2006; 1089: 36-58.

105. Trosko JE. Reprogramming or selection of adult stem cells. Stem Cell Rev. 2008; 4: 81-88.

106. Trosko JE. Human adult stem cells as targets for cancer stem cells Evolution; Oct-4 gene and cellcell communication. In: Dittmar T and Zaenkar K, editors. Stem Cells and Cancer, Hauppauge, NY: Nova Science. Pp. 147-187. 2008.

107. Trosko JE. Cancer stem cells and cancer non-stem cells: from adult stem cells or from reprogramming of differentiated somatic cells. Vet Pathol. 2009; 46: 176-193.

108. Trosko JE. Cancer: a stem cell-based disease. In Zaenkar KS, Dittmar $\mathrm{T}$, editors. Stem cell biology in health and disease. Heidelberg: Springer. Pp. 185-222, 2009.

109. Trosko JE. Human adult stem cells as the target cells for the initiation of carcinogenesis and for the generation of "cancer stem cells." Int ] Stem Cells. 2008; 1: 8-26.

110. Weinstein IB, Gattoni CS, Kirschmeier P, et al. Multistage carcinogenesis involves multiple genes and multiple mechanisms. Cell Physiol. 1984; 121(3): 127-37.

111. Pitot HC, Dragon YP. Facts and theories concerning the mechanism of carcinogenesis. FASEB J. 1991; 5: 2280-86.

112. Pitot HC. Progression: the terminal stage in carcinogenesis. Jpn J Cancer Res. 1989; 80: 599-607.

113. Trosko JE. Cancer: A Stem Cell-based disease?, In: Stem Cell Biology in Health and Disease. K. S. Zaenkar and T. Dittmar, Springer Publishers, Heidelberg. pp. 185-222, 2009.

114. Goldsworthy TL, Campbell HA, Pitot HC. The natural history and dose-response characteristics of enzyme altered foci in rat liver following phenobarbital and diethyl nitrosamine administration. Carcinogenesis. 1984; 5 (l): 67-71.

115. Goldsworthy TL, Hanigan MH, Pitot $\mathrm{HC}$, et al. Models of Hepatocarcinogenesis in the Rat-Contrasts and Comparisons, CRC Critical Reviews in Toxicology. 1986; 17: 1, 61-89, DOI: $10.3109 / 10408448609037071$.

116. Suzukawa K, Webe r T], Colburn NH. AP-1, NFkB, and ERK Activation
Thresholds for Promotion of Neoplastic Transformation in the Mouse Epidermal JB6 Model. Environmental Health Perspectives. 2002; 110 (9): 865-870.

117. Williams GM, Iatropoulos MJ, Jeffery AM. Thresholds for the effects of 2-Acetylaminofluorene in rat liver. Toxicol Pathol. 2004; 32 (Suppl 2): 85-91. DOI: $10.1080 / 01926230490451716$.

118. Pitot HC, Goldsworthy TL, Moran S, et al. A method to quantitate the relative initiating and promoting potencies of hepatocarcinogenic agents in their dose-response relationships to altered hepatic foci. Carcinogenesis. 1987; 78: 1491-1499.

119. Goodman JI. Operational reversibility is a key aspect of carcinogenesis. Toxicol Sci. 2001 64(2): 147-148.

120. Ghulam H. Kalimi, Satyavati M. Sirsat' Phorbol ester tumor promoter affects the mouse epidermal gap junctions. Cancer Letters. 1984; 22, (3): $343-350$

121. Firestone GL, Kapadia BJ. Minireview: Regulation of Gap Junction Dynamics by Nuclear Hormone Receptors and Their Ligands". Molecular Endocrinology. 2012; 26.11: 1798-1807.

122. Saez PJ, Shoji KF, Aguirre A, et al. Regulation of hemichannels and gap junctions channels by cytokines in antigen-presenting cells. Mediators Inflammation. 2014; 2014, Article ID 742734, 23 pages; http://dx.doi.org/10.1155/2014/742734

123. Même W, Falvo CF, F roger N, et al. Pro-inflammatory cytokines released from microglia inhibit gap junctions in astrocytes: potentiation by beta-amyloid. FASEB Journal. 2006; 20(3): 494-496.

124. Hansson E, Skiöldebrand E. Coupled cell networks are target cells of inflammation, which can spread between different body organs and develop into systemic chronic inflammation. Journal of Inflammation. $2015 ; 12: 44$.

125. Garré JM. FGF-1 triggers pannexin-1 hemichannels opening in spinal astrocytes of rodents and promotes inflammatory responses in acute spinal cord slices". Journal of Neuroscience. 2016; 36(17). 4785-4801.

126. Trosko JE, Chang CC. Nongenotoxic mechanisms in carcinogenesis: role of inhibited intercellular communication. In: Hart R and Hoerger FD (eds) Banbury Report 31: New Directions in the Qualitative and Quantitative Aspects of Carcinogen Risk Assessment, Cold Spring Harbor, NY: Cold Spring Harbor Press. Pp. 139-170, 1988.

127. Budunova IV, Williams GM. Cell culture assays for chemicals with tumor promoting or inhibiting activity based on the modulation of intercellular communication. Cell Biol Toxicol. 1994; 10: 71-116.

128. De Feijter AW, Ray JS, Weghorst CM, et al. Infection of rat liver epithelial cells with V-Ha-ras: Correlation between oncogene expression, gap junctional communication, and tumorigenicity. Molec. Carcinogenesis. 1990; 3: 54-67.

129. de Feijter-Rupp HL, Hayashi T, Kalimi GH, et al. Restored gap junctional communication in non-tumorigenic HeLa-normal human fibroblast hybrids. Carcinogenesis. 1998; 19(5): 747-754.

130. Upham B, Blaha L, Babica P, et al. Inhibition of intercellular signaling, a tumor promotion event, by a cigarette abundant $\mathrm{PAH}$, depends on phosphatidylcholine-specific phospholipase C. Cancer Sci. 2008; 99: 696-705.

131. Stellman SD, Takezaki T, Wang L, et al. Smoking and lung cancer risk in American and Japanese men: an international case-control study. Cancer Epidemiol Biomark Prev. 2001; 10: 1193-1199. 132. Zhou W, Heist RS, Liu G, et al.: Smoking cessation before diagnosis and survival in early stage nonsmall cell lung cancer patients. Lung Cancer. 2006; 53: 375-80.

132. Upham BL, Weis LM, Rummel AM, et al. The effects of anthracene and methylated anthracenes on gap junctional intercellular communication in rat liver epithelial cells. Fund Appl Toxicol. 1996; $34: 260-264$. 
133. Weis LM, Rummel AM, Masten SJ, et al. Bay or Baylike Regions of Polycyclic Aromatic Hydrocarbons Were Potent Inhibitors of Gap Junctional Intercellular Communication. Environ Health Perspect. 1998; 106: 17-22.

134. Jung JW, Park, SB, Lee SJ, et al. Metformin Represses Self-Renewal of the Human Breast Carcinoma Stem Cells via Inhibition of Estrogen Receptor-Mediated OCT4 Expression", PLoS One; http://dx.plos. org/10.1371/journal.pone.0028068.

135. Lopes JR, Arnosti DN, Trosko JE, et al. Melatonin decreases estrogen receptor binding to estrogen response elements(ERE) sites on Oct4 gene in human breast cancer stem cells". Genes \& Cancer. 2016; 7 9-14.

136. Androutsellis-Theotokis A, Walbridge S, Park DM, et al. Cholera toxin regulates a signaling pathway critical for the expansion of neural stem cell cultures from the fetal and adult rodent brains. PLoS One. 2010; 5(5): e10841. doi:10.1371/journal.pone.0010841.

137. Lindemans CA, Calafiore M, Mertelsmann AM, et al. Interleukin-22 promotes intestinal -stem cell-mediated epithelial regeneration. Nature. 2015; 528: 560-564.

138. Hsieh CY, Chang CC. Stem cell differentiation and reduction as a potential mechanism for chemoprevention of breast cancer". Journal of Chinese Pharmaceutical Sciences. 1999; 51: 15-30.

139. Trosko JE. Modulation of Cell-Cell Communication and Epigenetic Mechanisms as a Shared Cellular Mechanism in Diverse Childhood Brain Diseases, Such as Cancer and Autism. EC Neurology. 2018; 10(3): 134-156.

140. Hotamisligil GS. Inflammation and metabolic disorders. Nature 2006; 444: 860-867; DOI: 10.1038/nature05485.

141. Aller MA, Arias JL, Nava MP, et al. Posttraumatic inflammation is a complex response based on the pathological expression of the nervous, immune, and endocrine functional system. Exp Biol Med. 2004; 229: 170-181.

142. Willerson JT, Ridker PM. Inflammation as a cardiovascular risk factor Circulation. 2004; 109: 2-10.

143. 144. Beachy PA, Karhadkar SS, Berman DM. Mending and malignancy. Nature. 2004; 431: 402.

144. Tuppo EE, Arias HR. The role of inflammation in Alzheimer's disease. Int J Biochem Cell Biol. 2005; 37: 289-305.

145. Hand TW, Vulkovic-Cvijin I, Ridaura VK, et al. Linking the micriobiota, chronic disease, and the immune system. Trends in Endocrinology \& Metabolism. Trends in Endocrinology \& Medicine. 2016; 27(12): 831-843. http://dx.doi.org/10.1016/j.tem.2016.08.003.

146. Koh JH, Kim WU. Dysregulation of gut microbiota and chronic inflammatory disease: from epithelial defense to host immunity. Exp Mol Med. 2017; 49(5): e337. doi: 10.1038/emm.2017.55.

147. Ferreira C M, Vieira A T, Vinolo MAR, et al. The Central Role of the Gut Microbiota in Chronic Inflammatory Diseases. Journal of Immunology Research. 2014, Article ID 689492, 12 pages, 2014. https://doi.org/10.1155/2014/689492.

148. Campbell AK, Matthews SB. Darwin's illness revealed. Postgraduate Medical J. 81(954): http://dx.doi.org/10.1136/pgmj.2004.025569.

149. Adesse D, Goldenberg RC, Fortes FS, et al. Gap junctions and chagas disease. Adv Parasitol. 2011; 76: 63-81. doi: 10.1016/B978-0-12385895-5.00003-7.

150. Trosko JE, Tai MH. Adult stem cell theory of the multi-stage, multimechanism theory of carcinogenesis: Role of inflammation on the promotion of initiated cells". In: Infections and Inflammation: Impacts on Oncogenesis, T. Dittmar, K.S. Zaenker, and A. Schmidt, eds., S. Karger AG, Publisher, Contributions to Microbiology, Vol. 13 Infection and Inflammation: Impacts on Oncogenesis", XXXXXX pg. $45-65,2006$.
151. Kielan T, Esen N. Effects of neuroinflammation on glia-glia gap junctional intercellular communication: a perspective. Neurochem Intl. 2004; 45: 429-436.

152. ALTMAN LA. Discoverers of AIDS and Cancer Viruses Win Nobel. New York Times. OCT. 7, 2008.

153. Rhim JS. Neoplastic transformation of human cells in vitro. Crit Rev Oncogen. 1993; 4: 312-335.

154. Kuroki T, Huh NH. Why are human cells resistant to malignant cell transformation in vitro? Jpn J Cancer Res. 1993; 84: 1091-1100.

155. DiPaolo JA. Relative difficulties in transforming human and animal cells in vitro. J Natl Cancer Inst. 1983; 70: 3-8.

156. Viallet J, Liu C, Emond J, et al. Characterization of human bronchial epithelial cells immortalized by the E6 and E7 genes of human papillomavirus Type16. Exp Cell Res. 1994; 212: 36-41.

157. Bryan TM, Reddel RR. SV40-induced immortalization of human cells. Crit Rev Oncogen. 1994; 5: 331-357.

158. Land H, Parada IE, Weinberg RA. Tumorigenic conversion of primary embryo fibroblasts requires at least two cooperating oncogenes. Nature. 1983; 304: 596-602.

159. Kao CY, Nomata K, Oakley CS, et al. Two types of normal human breast epithelial cells derived from reduction mammoplasty: Phenotypic characterization and response to SV40 transfection. Carcinogenesis. 1995; 16: 531-538.

160. Lowy DR, Schiller JT. Reducing HPV-associated cancer globally. Cancer Prevention Research (Philadelphia) 2012; 5(1): 18-23.

161. Chang MH, Chen CJ, Lai MS, et al. Universal Hepatitis B vaccination in Taiwan and the incidence of hepatocellular carcinoma in children. The New England Journal of Medicine. 2015; 336 (26): 1855-1859.

162. He K, Nukada H, Urakami T, et al. Antioxidant and prooxidant properties of pyrroloquinoline quinine (PQQ): implications for its function in biological systems. Biochem Pharmocol. 2003; 65: 67-74.

163. Sporn MB, Dunlop NM, Newton DL, et al. Prevention of chemical carcinogenesis by vitamin $A$ and its synthetic analogs (retinoids). Fed Proc. 1976; 35: 1332-1338.

164. Henning H, Wenk ML, Dohahoe R. Retinoic acid promotion of papilloma formation in mouse skin. Cancer Letters. 1982; 16: 1-5.

165. Trosko JE. Bioethics: A philosophical basis for moral Decisions". Global Bioethics. 2002; 15: 55-59.

166. Barker DJ. The developmental origins of adult disease. J Am Coll Nutr. 2004; 236: 588s-595s.

167. Friedman TL. Thank You for Being Late. Farrar, Straus and Giroux, New York, NY, 2016.

168. Trosko JE. Global Health Crisis Caused by the Collision of Biological and Cultural Evolution: Pre Natal Influences on Acute and Chronic Diseases in Later Life. Planet@Risk. 2014; 2(4): 271-280.

169. Trosko JE. Global Bioethical Prevention of the Collision of Biological and Cultural Evolution on Miserable Human Survival. Sociology Study. 2015; 5(4): 295-313.

170. Wang $X$, Dai J. Concise review: isoforms of Oct4 contribute to the coinfusing diversity in stem cell biology. Stem Cells 2010; 28(5): 885-893.

171. Nichols J, Zevnik, B, Anastassiadis K, et al. Formation of pluripotent stem cells in the mammalian embryo depends on the POU transcription factor Oct4. Cell. 1998; 95(3): 379-391.

172. Takahashi K, Yamanaka S. A decade of transcription factor-mediated reprogramming to pluripotency. Nat Rev Mol Cell Biol. 2016; 17(3): 183-193. 